\title{
LA REANIMACIÓN DE LA PREVALENCIA. ¿UNA GRIETA ABIERTA EN NUESTRO MODELO CENTRALIZADO DE JUSTICIA CONSTITUCIONAL?'
}

\author{
The revival of the preemption. \\ A rupture in our centralized model of judicial review?
}

\author{
TOMÁS DE LA QUADRA-SALCEDO JANINI \\ Tribunal Constitucional \\ tquadra@tribunalconstitucional.es
}

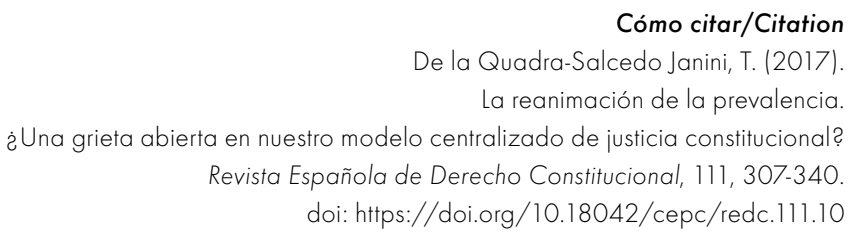

Resumen

La obligación que impone, con fundamento en el principio de prevalencia reconocido en el art. 149.3 CE, la nueva doctrina del Tribunal Constitucional a los órganos judiciales ordinarios de inaplicar la ley autonómica que contradiga la normativa básica estatal de manera sobrevenida supone una excepción al modelo centralizado de jurisdicción constitucional y genera dos consecuencias: una mayor inseguridad jurídica en relación con el sistema de distribución de competencias y la imposibilidad de que los parlamentos autonómicos defiendan la conformidad de la ley autonómica con aquel.

1 El presente trabajo se ha elaborado en el marco del proyecto de investigación «Formas de Participación política en los sistemas de gobierno multinivel y mejora de la Calidad Democrática (PACADE)», con referencia DER2015-68160-C3-1-P y dirigido por José Tudela Aranda. Agradezco a Javier Jiménez Campo, Jesús García Torres, Margarita Beladiez, Pedro Ibáńez e Ignacio Rodríguez haberme dado la ocasión de poder contrastar ideas. 


\title{
Palabras clave
}

Prevalencia; modelos de justicia constitucional; competencias compartidas.

\begin{abstract}
The obligation that a new jurisprudence of the Constitutional Court imposes on the ordinary judicial organs to not apply the autonomic law that contradicts the basic state regulation in application of the principle of prevalence recognized in art. 149.3 EC is an exception to the centralized model of judicial review and generates two consequences: greater legal uncertainty in relation to the constitutional system of distribution of powers and the impossibility for the autonomous parliaments to defend the conformity of the regional law with that system.
\end{abstract}

\section{Keywords}

Preemption; judicial review models; shared competences. 


\section{SUMARIO}

I. INTRODUCCIÓN. II. EL PRINCIPIO DE LA PREVALENCIA EN LA CONSTITUCIÓN:

1. Los principios constitucionales de resolución de conflictos normativos territoriales: los principios de competencia y prevalencia. 2. Los destinatarios de la prevalencia. 3. El presupuesto para la aplicación de la prevalencia. 4. ¿ Una pluralidad de reglas constitucionales de prevalencia?: 4.1. Supuestos en los que se aplica la regla de la prevalencia del derecho autonómico sobre el derecho estatal. 4.2. Los supuestos en los que se aplica la regla de la prevalencia del derecho estatal sobre el derecho autonómico. III. EL SUPUESTO CONTROVERTIDO DE APLICACIÓN DE LA PREVALENCIA: EL ÁMBITO DE LAS COMPETENCIAS COMPARTIDAS: 1. La doctrina constitucional tradicional que excluye el uso del principio de prevalencia en la resolución de los conflictos normativos entre la ley autonómica y las bases estatales. 2. La revocación de la doctrina tradicional en dos pasos: las SSTC 102/2016 y 204/2016: 2.1. Un primer paso: ¿̇una tímida revocación de la doctrina tradicional fundada en una suerte de doctrina del acto aclarado? 2.2. Un segundo paso: la generalización de la prevalencia en los supuestos de inconstitucionalidad mediata sobrevenida. IV. LAS CONSECUENCIAS DE LA NUEVA DOCTRINA SOBRE EL MODELO DE JUSTICIA CONSTITUCIONAL. BiBLIOGRAFía.

\section{INTRODUCCIÓN}

El principio de prevalencia recogido en el art. 149.3 de la Constitución, y cuyo uso por los jueces y tribunales ordinarios se encontraba en buena medida impedido desde hace más de dos décadas por la interpretación que del mismo venía haciendo la doctrina del Tribunal Constitucional (en adelante TC), ha sido devuelto a la vida con extraordinario vigor por el propio Tribunal en las recientes SSTC 102/2016, de 25 de mayo, y 204/2016, de 1 de diciembre.

La revocación de su doctrina previa sobre la prevalencia ha sido realizada por el $\mathrm{TC}$ en dos pasos sucesivos ${ }^{2}$. En las presentes páginas no nos interesa

2 Así, por un lado en la STC 102/2016, de 25 de mayo, y su progenie - las SSTC 116/2016, de 20 de junio, y 127/2016, de 7 de julio, y el ATC 167/2016, de 4 de octubre-, y por otro, en la STC 204/2016, de 1 de diciembre. El Tribunal ha dado un tercer paso con la STC 1/2017, de 17 de enero, que ha limitado la prevalencia a los supuestos de inconstitucionalidad sobrevenida, esto es, la inconstitucionalidad derivada de la modificación de las bases con posterioridad a la adopción de la ley autonómica. 
solo examinar los concretos asuntos que han desembocado en el citado cambio doctrinal, sino también revisitar el significado de la cláusula constitucional de prevalencia y las consecuencias que sobre nuestro modelo de justicia constitucional tiene la utilización de la misma.

Así, la imposición a los jueces ordinarios de la obligación de aplicar la prevalencia se produce en la nueva doctrina del TC en aquel supuesto que más controversia doctrinal ha generado: el supuesto de contradicción entre una ley autonómica y la normativa básica estatal. Ciertamente, la obligación impuesta a los órganos judiciales de aplicar el principio de prevalencia del derecho estatal sobre el derecho autonómico supone, en el concreto supuesto de aquellas normas autonómicas que entran en contradicción de manera sobrevenida con las normas básicas estatales consideradas como tales, la puesta en cuestión del monopolio de rechazo del TC en virtud del cual se impediría a los jueces ordinarios por su propia autoridad inaplicar aquellas leyes que contradicen, mediata o inmediatamente, la Constitución. Sin embargo, cabría plantearse si tal puesta en cuestión del modelo centralizado de justicia constitucional no derivaría de la propia previsión del principio de prevalencia recogida en el art. 149.3 de la Constitución ${ }^{3}$.

Así sería posible sostener que es nuestra propia norma fundamental la que ha establecido un modelo centralizado de justicia constitucional con excepciones desde el momento en el que la misma ha previsto la posibilidad de que determinadas normas con rango de ley sean inaplicadas por los jueces ordinarios aun cuando ello suponga en la práctica la realización de un juicio de contradicción mediato con la Constitución.

\section{EL PRINCIPIO DE LA PREVALENCIA EN LA CONSTITUCIÓN}

\section{LOS PRINCIPIOS CONSTITUCIONALES DE RESOLUCIÓN DE CONFLICTOS NORMATIVOS TERRITORIALES: LOS PRINCIPIOS DE COMPETENCIA Y PREVALENCIA}

Como tempranamente señaló el TC, «la Constitución prefigura una distribución vertical del poder público entre entidades de distinto nivel» y entre

3 García Torres (1988: 281-282), tras destacar que eran los jueces y tribunales los destinatarios de la cláusula de prevalencia - la cual se convierte en fundamento del control judicial de la conformidad del derecho autonómico al derecho estatal prevalente-, subrayó que ello suponía que el control difuso podría concurrir en ciertos casos con el control concentrado del TC. 
las que identifican al Estado, titular de la soberanía, y a las comunidades autónomas, caracterizadas por su autonomía política (STC 32/1981, de 28 de julio, FJ 3).

La distribución vertical del poder público entre el Estado y las comunidades autónomas se perfecciona a través de aquellas normas atributivas y delimitadoras de las respectivas competencias. Normas incluidas en la propia Constitución — cuando dispone en el apartado 1 del art. 149 CE un listado de materia reservadas al Estado- , o a las que se remite esta — como es el caso del primer inciso del art. 149.3 CE cuando dispone que "las materias no atribuidas expresamente al Estado por esta Constitución podrán corresponder a las Comunidades Autónomas, en virtud de sus respectivos Estatutos»-

Los estatutos de autonomía se constituyen por tanto, además de en la norma fundacional de la correspondiente comunidad autónoma (arts. 143 y $151 \mathrm{CE}$ ), en la norma expresiva de su acervo competencial (art. 147.2 CE), pues son ellos los que dentro de los límites de las competencias reservadas constitucionalmente al Estado (fundamentalmente en el art. 149.1 CE) atribuyen competencias a las respectivas comunidades autónomas ${ }^{4}$.

Asimismo, la norma fundamental ha establecido una cláusula residual de competencias a favor del Estado al disponer en el segundo inciso del art. 149.3 $\mathrm{CE}$ que «la competencia sobre las materias que no se hayan asumido por los Estatutos de Autonomía (pudiendo haberlo sido por no ser materias atribuidas expresamente al Estado por la Constitución) corresponderá al Estado».

El modelo de distribución competencial fundado por nuestra Constitución en torno a las distintas normas atributivas de competencias (listado del art. 149.1 CE, cláusula residual del art. 149.3, estatutos de autonomía o normas del art. 150) debe, no obstante, completarse con el importante papel que juegan en el modelo determinadas normas delimitadoras del alcance de aquellas. En efecto, el TC ha entendido que, junto a las normas atributivas de competencias, nuestra Constitución ha previsto, asimismo, normas que, sin ser propiamente atributivas de competencias, son, sin embargo, normas delimitadoras del alcance de las competencias atribuidas en otras normas. Así, la Constitución ha remitido al legislador básico estatal la delimitación de las competencias al reservarle/atribuirle la competencia sobre las bases, pues «aun careciendo las normas básicas estatales de efectos atributivos de competencias que puedan alterar el sistema constitucional y estatutario, tienen [las normas básicas] por objeto delimitar, con alcance general, el espacio normativo al que

4 Ciertamente la ampliación competencial extraestatutaria es posible a través de otros instrumentos previstos en la Constitución, como la ley marco (art. 150.1 CE) y la ley orgánica de transferencia y delegación (art. 150.2 CE). 
las Comunidades Autónomas deben circunscribirse cuando ejercitan las competencias propias que tengan en relación con la materia que resulte delimitada por dichas normas básicas» (STC 69/1988, FJ 5) ${ }^{5}$. Por tanto las normas básicas del Estado, en la medida en que vienen a fijar indirectamente el alcance preciso del ámbito en el que las comunidades autónomas pueden ejercitar legítimamente sus competencia, «operan como canon en el control de la constitucionalidad de las leyes autonómicas» (STC 163/1995, FJ 4). Así, una ley autonómica que contradice una ley básica estatal adoptada dentro de sus márgenes constitucionales incurre en una inconstitucionalidad mediata o indirecta y vulnera el orden constitucional de distribución de competencias ${ }^{6}$.

El principio de competencia se constituye en la regla fundamental a la hora de resolver los conflictos que se pueden producir entre las normas de las comunidades autónomas y la del Estado al permitir determinar qué materias han quedado constitucional y estatutariamente atribuidas y con qué concreto alcance a las comunidades autónomas y al Estado?.

No obstante lo anterior, la Constitución ha previsto, junto al principio de competencia, un segundo principio como regla de resolución de aquellos conflictos normativos que puedan surgir entre las normas del Estado y las de las comunidades autónomas: el principio de prevalencia. De acuerdo con el segundo inciso del apartado 3 del art. $149 \mathrm{CE}$, "la competencia sobre las materias que no se hayan asumido por los Estatutos de Autonomía corresponderá al Estado, cuyas normas prevalecerán, en caso de conflicto, sobre las de las Comunidades Autónomas en todo lo que no esté atribuido a la exclusiva competencia de éstas».

El principio de prevalencia es una regla de conflicto que tiene por finalidad resolver cuál es la norma aplicable cuando dos normas colisionan, sin que

5 Tal concepción jurisprudencial supone reconocer la capacidad del legislador básico estatal para delimitar en cada momento, con ciertos límites, el alcance de su propia competencia y por reflejo el alcance de las competencias autonómicas, concepción que tiene como corolario la aceptación de que «siendo mudables las bases también lo es, en correspondencia inevitable, el ámbito disponible por la legislación de desarrollo» (STC 31/2010, FJ 60).

6 Tras la reciente jurisprudencia del TC en relación con la prevalencia propone Alonso Mas (2017) negar de modo absoluto la condición de parámetro de lo básico; lo que implicaría la inviabilidad de los recursos de inconstitucionalidad contra la norma autonómica contradictoria con la básica.

7 Señala De Otto (1987: 90-91) cómo «mientras en la jerarquía formal la invalidación de una norma, inferior, solo se produce si hay contradicción con otra, superior, en la distribución de materias tal contradicción no es precisa, sino que la norma resulta nula por el simple hecho de haber regulado la materia vedada». 
sirva a los efectos de determinar cuál es el nivel territorial competente para adoptar una determinada regulación, determinación que debe ser alcanzada a través del principio de competencia. La determinación de la norma aplicable a través del principio de prevalencia no comporta la derogación ni la nulidad de ninguna de las normas en conflicto ${ }^{8}$.

Recordado lo anterior, la cuestión fundamental que se ha suscitado doctrinalmente es la determinación de en qué supuestos cabe acudir a la regla de la prevalencia para resolver colisiones normativas.

Para poder responder a tal cuestión se debe examinar en primer lugar quiénes son los destinatarios naturales de la regla de la prevalencia para luego examinar en qué supuestos cabe aplicar la misma.

\section{LOS DESTINATARIOS DE LA PREVALENCIA}

Como se ha señalado, el destinatario de la cláusula de prevalencia no es nunca el juez constitucional, cuya misión no es resolver conflictos de leyes sino resolver acerca de la constitucionalidad de estas9. Así, la jurisdicción constitucional nada tiene que decir en relación con la aplicación de las leyes, pues la finalidad de los procesos de control de constitucionalidad que se sustancian ante ella es determinar si una ley es o no inconstitucional, para lo cual el TC utilizará el principio de competencia.

Los destinatarios naturales de la cláusula de prevalencia son los aplicadores del derecho, tanto los órganos judiciales ordinarios ${ }^{10}$ como la Administración $^{11}$. Cuando estos aplican la prevalencia no están realizando formalmente una delimitación competencial sino determinando la norma aplicable al caso.

8 Así lo recuerda Borrajo Iniesta (2009: 2495). Ello significa que la «preferencia» dada a una norma en virtud del principio de prevalencia nada dice acerca de la hipotética invalidez de la norma desplazada.

9 Rubio Llorente (1989: 33-34) y García Torres (1988:281-282). En el mismo sentido se pronuncia Tornos Mas (1991: 34), para quien la prevalencia no es regla aplicable por el TC, pues este no debe escoger la norma aplicable para resolver el caso, sino que se pronuncia sobre la validez de la ley en relación al bloque de constitucionalidad.

10 Para Hernández Corchete (2017: passim), sin embargo, la prevalencia del derecho estatal no se proyecta en el ámbito de la aplicación judicial del derecho, supuesto en el que cabe la posibilidad de planteamiento de la cuestión de inconstitucionalidad. Para este autor el verdadero espacio de aquella sería en el momento de su aplicación administrativa.

11 Las relevantes cuestiones que plantea la aplicación por parte de la Administración, imposibilitada para plantear cuestiones de inconstitucionalidad, del principio de prevalencia no son objeto de estas páginas. 


\section{EL PRESUPUESTO PARA LA APLICACIÓN DE LA PREVALENCIA}

No obstante, si bien el principio de prevalencia no constituye propiamente una regla de delimitación de competencias sino una regla de resolución de conflictos de normas a través de la determinación de la norma aplicable, ello no significa que el principio pueda actuar al margen de las competencias atribuidas. El principio de prevalencia es un instrumento de resolución de los conflictos normativos a través de la determinación de la norma aplicable al que solo pueden acudir los órganos judiciales una vez que han hecho uso del principio de competencia para determinar la validez de, al menos, la norma a la que se le vaya a otorgar prevalencia ${ }^{12}$, pues de no ser así se dejaría en manos del poder que haya dictado aquella norma la posibilidad de vulnerar la delimitación de competencias realizada por el bloque de la constitucionalidad (De Otto 1981: 63). Por tanto, aunque es cierto que el principio de prevalencia es una regla de colisión y no una regla de delimitación de competencias, el principio solo opera cuando el órgano encargado de aplicar la regla ha determinado la validez de la norma a la que se pretende otorgar carácter prevalente ${ }^{13}$, determinación que se realiza a través del principio de competencia. Ciertamente, tal juicio positivo de validez lo pueden realizar los órganos judiciales, pues nuestro modelo de justicia constitucional concentra en el TC el monopolio de rechazo de la ley pero no el de los juicios positivos de constitucionalidad ${ }^{14}$.

Es en este concreto punto en el que surge la discrepancia doctrinal más relevante en lo que se refiere a los supuestos de aplicación de la cláusula de prevalencia por parte de sus destinatarios naturales, los jueces y tribunales ordinarios.

12 De ser negativo el juicio de validez de la norma con vocación de prevalecer habrá de plantearse cuestión de inconstitucionalidad ante el TC.

13 Para Jiménez Campo (1989: 85) el juego de la cláusula de prevalencia no depende del previo examen acerca de la validez de la disposición autonómica sino de la apreciación de si la regla estatal tiene tras de sí algún título competencial que pueda justificar su aplicación incondicionada en todo el territorio. Para este autor, "cuando este examen preliminar sea resuelto positivamente (por el juez ordinario), la disposición autonómica, válida o no, ha de ser desplazada, en su pretendida aplicación al caso, por la estatal, conclusión que no admite más excepción que la que pudiera fundarse en la duda sobre la validez competencial del precepto del Estado".

14 En efecto, en nuestro modelo a la jurisdicción constitucional le está reservado el juicio sobre la validez de la ley, pero no, cualquier juicio de legibus, como es - para el caso- el de la colisión y selección entre normas. 
Para un sector doctrinal ${ }^{15}$, y para la doctrina anterior a la STC 102/2016, la cláusula de prevalencia presupone siempre un juicio de validez competencial de las dos normas en conflicto ${ }^{16}$. Ello implica que la cláusula de prevalencia solo podrá solucionar conflictos entre normas competencialmente válidas, lo cual supone excluir la aplicación de tal cláusula por los órganos judiciales en los concretos supuestos en los que una ley autonómica contradiga una norma básica estatal, pues en tales supuestos tal contradicción constituye una vulneración del orden constitucional de distribución de competencias que determina la invalidez de la norma autonómica.

Sin embargo, y en oposición a aquella concepción, para otro sector doctrinal ${ }^{17}$ la cláusula de prevalencia presupone únicamente la realización de un juicio de validez de la norma con pretensión de prevalecer pero no la realización de un juicio de validez de la norma a desplazar. En efecto, bajo esta segunda concepción, el principio de prevalencia no le exige al juez ordinario preguntarse acerca del título competencial que tiene tras de sí la ley autonómica, sino que le exige preguntarse únicamente acerca de si existe un título competencial estatal que le permita regular tal materia, pues una vez ha considerado que existe competencia estatal, la eventual contradicción de la ley autonómica con la norma estatal determinaría la inaplicabilidad de aquella en virtud del principio de prevalen$\mathrm{cia}^{18}$. Ello no es óbice para que, bajo la interpretación de este sector doctrinal, quepa entender abierta la vía del recurso de inconstitucionalidad para controlar la validez de la norma autonómica ${ }^{19}$. Así, en el caso de tratarse de un supuesto de contradicción de una ley autonómica con una ley básica estatal, aquella no deja de incurrir en una inconstitucionalidad «mediata o indirecta» que podría ser declarada por el TC. La determinación de la validez o invalidez de las disposiciones autonómicas «tiene su cauce de planteamiento y resolución en los conflictos de competencias y recursos de inconstitucionalidad de los que conoce el

15 Entre los cuales encontraríamos, por ejemplo, a De Otto (1987); Fernández Farreres (1991); García de Enterría y Fernández Rodríguez (1999: 338); Muñoz Machado (2006); Aragón Reyes (2008: XVII) o Arroyo Gil (2009).

16 Señala Tornos (1991: 35) que a la realización de tal interpretación coadyuva la dicción de la cláusula recogida en el art. 149.3, pues introduce en su contenido una regla competencial que distorsiona su funcionamiento al parecer que el órgano judicial debe examinar en primer lugar si la competencia es o no exclusiva de la comunidad autónoma.

17 Entre los cuales estarían García Torres (2015); Rubio Llorente (1989), Jiménez Campo (1989) y más recientemente Padrós Reig y González Barral (2017).

18 Para Rubio Llorente (1989: 33) la concentración en manos del TC del monopolio de rechazo (Verwerfungsmonopol) solo existe respecto de las leyes del Estado.

19 En relación a la dualidad aplicabilidad-validez véase Requejo Pagés (2016). 
Tribunal Constitucional» (Jiménez Campo, 1989: 86). Sin embargo, bajo esta concepción el órgano judicial no se encuentra obligado a plantear la cuestión de inconstitucionalidad frente a la ley autonómica, pues el principio de prevalencia del art. 149.3 le permitiría resolver el conflicto determinando la aplicabilidad de la norma básica estatal ${ }^{20}$.

Así, un mismo juicio, la compatibilidad de la ley autonómica con la norma básica estatal, tendría, bajo la última concepción señalada, una distinta consecuencia dependiendo de quién haga tal juicio, pues si lo realiza el TC, en trance de resolver un recurso de inconstitucionalidad frente a ella, la consecuencia en caso de incompatibilidad será la invalidez de la norma autonómica con efectos erga omnes, mientras que si lo realiza un órgano judicial la consecuencia, en virtud del art. 149.3 CE, será la inaplicabilidad de la ley autonómica y la aplicación de la norma básica estatal en el caso concreto ${ }^{21}$.

Antes de profundizar en lo que supone la señalada discrepancia doctrinal en el concreto supuesto de la contradicción entre una ley autonómica y la normativa básica estatal, conviene examinar aquellos otros supuestos en lo que el juicio de compatibilidad entre las dos normas en conflicto, estatal y autonómica, no puede desembocar en la invalidez de una de las normas en conflicto, por no ser ninguna de ellas parámetro de validez de la otra, sino en su inaplicabilidad. En este punto cabe diferenciar los supuestos en los que la norma prevalente es la norma autonómica de aquellos otros en los que la norma prevalente es la estatal, pues en nuestro sistema constitucional de distribución de competencias también se ha establecido implícitamente la previsión de supuestos de prevalencia autonómica.

\section{4. ¿UNA PLURALIDAD DE REGLAS CONSTITUCIONALES DE PREVALENCIA?}

Se ha señalado que la Constitución recogería en el art. 149.3 CE dos reglas de prevalencia distintas ${ }^{22}$.

20 Lasagabaster Herrarte (1991: 145 y ss.), de manera más matizada, considera que los órganos judiciales pueden aplicar la prevalencia cuando la contradicción se produce como consecuencia de la modificación de las bases del Estado con posterioridad a la adopción de la ley autonómica, pero no en el supuesto de una contradicción con las bases del Estado por la ley autonómica posterior a estas

21 En este sentido «una cosa es el acto intelectual (juicio de compatibilidad) y otra los efectos vinculados a ese juicio según quién sea el operador que lo formula» (García Torres, 2016: 5).

22 A la cláusula de prevalencia dual se refirió Balaguer Callejón (1986: 117-118). 
Por un lado aquella regla que dispone la prevalencia de las normas del Estado sobre las de las comunidades autónomas («cuyas normas [las del Estado] prevalecerán, en caso de conflicto, sobre las de las comunidades autónomas»), pero por otro aquella regla que establece una excepción a tal prevalencia (pues las normas del Estado solo prevalecen «en todo lo que no esté atribuido a la exclusiva competencia de éstas») y que puede desembocar en la práctica en el reconocimiento de una prevalencia de las normas autonómicas ${ }^{23}$ sobre las estatales en determinados supuestos.

\subsection{Supuestos en los que se aplica la regla de la "prevalencia» del derecho autonómico sobre el derecho estatal}

Así, en efecto, es posible identificar determinados supuestos en los que los órganos judiciales no deberían aplicar la prevalencia del derecho estatal válido sobre el derecho autonómico válido, sino la de este último sobre aquel:

a) De acuerdo con la primera frase del artículo $149.3 \mathrm{CE}$, «las materias no atribuidas expresamente al Estado por esta Constitución podrán corresponder a las Comunidades Autónomas, en virtud de sus respectivos Estatutos", y de acuerdo con la segunda frase del mismo precepto, "la competencia sobre las materias que no se hayan asumido por los Estatutos de Autonomía corresponderá al Estado».

La Constitución ha vinculado el principio de autonomía con el llamado principio dispositivo (art. 147.2, en conexión con el art. 149.3 CE), que otorga un importante margen de decisión al legislador estatutario y posibilita la existencia de «diferencias entre los Estatutos de las distintas Comunidades Autónomas».

Dada la potencial heterogeneidad que en el sistema español tienen los ámbitos competenciales de las distintas comunidades autónomas, es posible la existencia de un derecho estatal posconstitucional fundado en el ejercicio de la cláusula residual recogida en la segunda frase del art. 149.3 CE. Derecho estatal que es válido y directamente aplicable en aquellas comunidades autónomas que no hayan asumido competencias en la concreta materia, pero que sería derecho válido pero inaplicable en el territorio de aquellas otras comunidades autónomas que sí hayan asumido la competencia en la materia

23 A esta segunda regla de prevalencia De Otto (1981: 85 y ss.) la denomina principio de especialidad. 
como propia ${ }^{24}$. En estas últimas comunidades autónomas el derecho estatal, sin duda válido, solo podría ser aplicado como derecho supletorio en virtud de lo dispuesto en la tercera frase del art. 149.3 C.E. («El derecho estatal será, en todo caso, supletorio del derecho de las Comunidades Autónomas»).

La limitación del derecho estatal adoptado en virtud de la cláusula residual en términos de aplicabilidad o vigencia territorial, y no en términos de validez, sería coherente con la peculiar estructura de nuestro Estado autonómico y, en concreto, con dos características del mismo: no es jurídicamente obligado que todo el territorio nacional se constituya en comunidades autónomas y no todas las comunidades autónomas han de tener las mismas competencias (De Otto, 1981).

b) Es asimismo posible que el derecho [estatal] válido devenga inaplicable y el aplicable sea el derecho autonómico en el supuesto del derecho preconstitucional, pues este sigue vigente en lo que no se oponga materialmente a lo dispuesto en la Constitución ${ }^{25}$, pero se verá paulatinamente desplazado cuando las comunidades autónomas hayan asumido competencias en la materia regulada y las hayan efectivamente ejercido. No obstante lo cual el derecho [estatal] preconstitucional puede quedar como derecho supletorio.

c) Algún sector doctrinal se refirió en su día a un tercer supuesto de derecho estatal válido pero que no prevalecería sobre el derecho autonómico. Se trataría del derecho estatal dictado con fundamento en la cláusula de supletoriedad recogida en el art. 149.3 $\mathrm{CE}^{26}$. Para De Otto, en el Estado autonómico la competencia normadora del Estado central no tiene límites, es una

24 El TC tempranamente en la STC 5/1981, de 13 de febrero de 1981, consideró que el hecho de que una norma estatal tratase materias sobre las que pudiesen haber legislado los órganos competentes de las comunidades «no significa que [los preceptos estatales] sean inconstitucionales», pues el supuesto conflicto «no afectaría para nada a su validez en el resto del territorio espańol» ya que, en los territorios autonómicos que hubiesen legislado, los preceptos estatales «se verán afectados por las posibles leyes de las Comunidades pasando a ser en éstas derecho supletorio y no derecho aplicable en primer término».

25 Para el TC «la promulgación de la Constitución no ha roto la continuidad del orden jurídico preconstitucional más que con respecto a aquellas normas que no pueden ser interpretadas de conformidad con la Constitución» STC 32/1981, de 28 de julio.

26 Señala Lasagabaster Herrarte (1991: 51) que «se admite que el Estado pueda seguir dictando normas en materias de competencia autonómica sin que la distribución competencial afecte a la validez de estas disposiciones, aunque sí se verá afectada su eficacia». 
competencia general ${ }^{27}$. Allí donde tenga competencia la comunidad autónoma, la norma estatal dictada en ejercicio de su competencia general tendrá una vigencia de segundo grado, es decir, será de aplicación supletoria (De Otto, 1981: 75 y 76). La razón que le lleva a De Otto a interpretar que el Estado tiene competencia general es la interpretación que realiza del principio de supletoriedad como regla atributiva de competencias, pues tal principio «está afirmando, obviamente, que tal supletoriedad se dará también cuando el derecho del Estado se ocupe de materias que corresponden a la competencia de las Comunidades Autónomas».

Tal concepción ha sido, sin embargo, abandonada por la jurisprudencia constitucional ${ }^{28}$, que, desde finales de los ańos 80 , considera que la regla de supletoriedad del derecho estatal del art. 149.3 de la Constitución «no constituye una cláusula universal atributiva de competencias para legislar sobre cualesquiera materias a favor del Estado (SSTC 15/1989 y 103/1989), porque obviamente no es una norma competencial sino ordenadora de la aplicación de las normas en el Estado compuesto configurado por la Constitución» (STC 147/1991, de 4 de julio, FJ 7$)^{29}$.

Por tanto, y recapitulando, en aquellos supuestos en los que el derecho estatal se haya dictado en ejercicio de la cláusula residual (art. 149.3 CE) o sea derecho preconstitucional, prevalecerá el derecho autonómico que se haya dictado en las correspondientes materias en ejercicio de las competencias estatutariamente atribuidas.

27 Señala Díez Picazo (1989: 70 y 84) que de acuerdo con la concepción doctrinal dominante «el legislador estatal es omnicompetente: no hay materia alguna, en principio, cuya regulación le esté vedada», si bien este autor se desmarca de tal concepción al sostener la necesidad de interpretar que «solo es legislación estatal válida - y, por tanto, apta para ser supletoria - la que respeta los límites competenciales del Estado central, ya que la supletoriedad solo puede ser un complemento de la competencia». Si bien en la STC 130/2013 se ha venido a matizar la doctrina general al reconocer como una excepción que en el ámbito de la ejecución de la Unión Europea sí cabe que el Estado produzca normas de carácter meramente supletorio (Quadra-Salcedo Janini, 2013).

29 Para el Tribunal «será, por consiguiente, ilegítima, por invasión competencial, aquella ordenación estatal de materias que hayan sido deferidas por los Estatutos de Autonomía a la competencia exclusiva de todas y cada una de las respectivas Comunidades Autónomas y en relación con las cuales el Estado no invoque algún título propio que le permita dictar normas generales sobre dichas materias" STC 147/1991, de 4 de julio, FJ 7. De esta doctrina el propio Tribunal extrajo importantes consecuencias en las SSTC 118/1996, de 27 de junio, y 61/1997, de 20 de marzo. 
A tales supuestos cabe interpretar que se refiere el texto constitucional cuando excepciona la prevalencia del derecho estatal sobre el autonómico en el ámbito de la exclusiva competencia de las comunidades autónomas, pues «la exclusividad autonómica ante la que la prevalencia se detiene no es la que, respecto de materias inevitablemente abstractas afirman los Estatutos ${ }^{30}$, sino la que proviene de la inexistencia de título estatal recogido en el listado del art. 149.1 CE. En efecto, en aquellos supuestos en los que el derecho estatal se haya dictado en legítimo ejercicio de las competencias reservadas al Estado en el art. 149.1 CE, el mismo prevalecerá sobre el derecho autonómico ${ }^{31}$.

\subsection{Los supuestos en los que se aplica la regla de la prevalencia del derecho estatal sobre el derecho autonómico}

Una vez hemos examinado los supuestos en los que se aplica la regla de prevalencia del derecho autonómico sobre el derecho estatal, debemos examinar aquellos otros supuestos en los que cabe sostener la posibilidad de que los órganos judiciales apliquen la regla de prevalencia del derecho estatal sobre el derecho autonómico.

30 Jiménez Campo (1989: 85 y 86). Para García de Enterría (1985: 359-363) la exclusividad no se refiere tanto al carácter de la competencia o a la modalidad de atribución cuanto a la posibilidad de actuar con exclusividad, excluyendo simultáneamente la actuación del Estado.

31 Esta es la interpretación del principio de prevalencia del derecho estatal que se realizaba en el Informe de la Comisión de Expertos sobre Autonomías, pp. 46 y 47, donde se seńalaba que «el sentido evidente del precepto es que cuando el Estado dispone de competencias exclusivas sobre una materia o son sus competencias legislativas concurrentes, las normas que emanen priman sobre las de las Comunidades Autónomas [...] La Comisión entiende que la interpretación correcta del precepto exige conceder la primacía de la legislación estatal que recaiga sobre cualquiera de las materias enumeradas en el propio art. 149».

El art. 4 de la LOAPA reflejaba esta idea cuando afirmaba que «las normas que el Estado dicte en ejercicio de las competencias que le reconoce el art. 149.1 CE prevalecerán sobre las normas de las CCAA». Tornos Mas (1984:149-150) subrayó que ello suponía convertir el principio de prevalencia de norma de conflicto en norma de competencia, pues permite determinar el ámbito de validez del derecho autonómico. Sin embargo, cabe señalar que solo prevalecerán aquellas normas que el Estado dicte en ejercicio legítimo de las competencias que le reconoce el art. 149.1 CE, por lo que siempre cabe que el órgano judicial se plantee la validez de la norma con vocación de prevalecer. 
a) Un primer supuesto, no pacífico, sería aquel en el que se produce una colisión de normas adoptadas en ejercicio de títulos competenciales materiales propios y distintos de cada uno de los dos niveles territoriales. Un sector doctrinal ha sostenido que, una vez apurado el principio de competencia como regla de deslinde competencial y ante la dificultad de distinguir las competencias atribuidas a cada nivel, se acuda al principio de prevalencia para determinar la norma aplicable.

En efecto, se ha señalado que la falta de perfección de cualquier reparto de competencias supondría que puede producirse la concurrencia de normas provenientes de los diversos niveles territoriales «cuando regulaciones que tienen un objeto material distinto se solapan o coinciden en algunos aspectos, situación que es difícil de evitar en la práctica, dada la difícil concreción del contenido de cada materia y su separación neta de las demás» (Muñoz Machado, 1982: 407; García de Enterría y Fernández Rodríguez, 1999: 341 y ss.). Para este sector doctrinal la solución a tal concurrencia, una vez se haya apurado el intento de deslinde competencial, pasaría por reconocer la prevalencia de la norma estatal sobre la autonómica (García de Enterría y Fernández Rodríguez, 1999: 336 y ss.; Tejedor Bielsa, 2000: 90 y ss.). En estos supuestos de concurrencia de competencias materiales la aplicación de la prevalencia de la norma estatal tendría como efecto la aplicación preferente de la norma estatal con la consiguiente inaplicación de la autonómica sin que ello suponga la asignación de la materia al Estado, pues en los supuestos de superposición de títulos no se resuelve el conflicto mediante la declaración de invalidez de la norma autonómica por haberse dictado sin tener competencia para ello, pues competencia la tiene, sino que se resuelve mediante la inaplicabilidad de la norma autonómica en virtud del principio de prevalencia ${ }^{32}$.

Sin embargo, pese a poderse admitir la dificultad a la hora de escindir la realidad en materias, se ha señalado que ello no debería ser impedimento para que jurídicamente se deba intentar realizar tal escisión sin, por tanto, acudir directamente al «socorrido» recurso de dar prevalencia a la disposición estatal $^{33}$.

En este sentido, García Morales (2015: 71 y ss.).

33 Viver i Pi-Sunyer (1989). Así, para un sector doctrinal la solución de un conflicto entre normas adoptadas en virtud de competencias distintas vendría a través de una adecuada delimitación competencial pero no a través del principio de prevalencia, pues «por definición los conflictos o colisiones no pueden en principio producirse si una y otra norma se han dictado sin extralimitación competencial» (Fernández Farreres, 1991: 545). El propio Fernández Rodríguez (1979: 850) sostuvo con anterioridad que este tipo de conflictos de carácter fronterizo no se resuelven haciendo 
b) Un segundo supuesto sería aquel en el que también se produce, como en el supuesto anterior, una colisión de normas adoptadas en ejercicio de títulos competenciales propios y distintos de cada uno de los dos niveles territoriales. Sin embargo, la diferencia con aquel estaría en que en este segundo supuesto, el título competencial estatal no se define materialmente sino que es un título competencial horizontal, que como tal, precisamente, tiene vocación de permitir que el Estado regule en ámbitos materiales atribuidos estatutariamente a las Comunidades Autónomas (Quadra-Salcedo Janini, 2008).

El ejercicio efectivo de estas competencias horizontales ${ }^{34}$ puede dar lugar a la concurrencia práctica, que no competencial, de normas adoptadas en ejercicio de competencias distintas, una definida materialmente, la autonómica, y otra definida funcionalmente, la estatal. El hecho de ser colisiones de normas que han sido adoptadas en ejercicio de competencias distintas es lo que diferencia esta concurrencia práctica de la concurrencia competencial que se produce como consecuencia de la adopción de normas por los dos niveles territoriales en ejercicio de una misma competencia material que ha sido simultáneamente atribuida a ambos niveles territoriales y a la que nos referiremos bajo el supuesto c). La atribución estatutaria de competencias materiales a las comunidades autónomas determina el reconocimiento de la capacidad de estas para regular tales materias, pero tal atribución estatutaria, en sí misma, no supone la exclusión de la posibilidad de que las regulaciones autonómicas se vean afectadas por aquellas regulaciones del Estado adoptadas en ejercicio de aquellas competencias transversales que le reserva nuestra Constitución en

prevalecer el derecho de uno de los poderes sino precisando y delimitando la línea fronteriza mediante el correspondiente deslinde.

34 Tal sería el caso de la competencia recogida en el art. 149.1.1 CE, que reserva al Estado «la regulación de las condiciones básicas que garantizan la igualdad de todos los espańoles en el ejercicio de los derechos y en el cumplimiento de los deberes constitucionales». De forma más discutible tal podría ser el caso también de la competencia recogida en el art. 149.1.13 CE, que ha sido interpretado por el TC como una competencia estatal sobre la ordenación general de la economía, la cual «haría posible la intervención del Estado a través de medidas económicas en sectores materialmente atribuidos a la competencia de las Comunidades Autónomas» (STC 186/1988, de 17 de octubre, FJ 8). Sin embargo, no obstante haber considerado la competencia estatal sobre ordenación general de la economía como una competencia horizontal, al tiempo el TC, en los recursos de inconstitucionalidad que ha resuelto, no ha dejado de considerarla una competencia sobre lo básico, lo cual ha llevado al Tribunal a sostener que la compatibilidad de la ley autonómica con las normas dictadas por el Estado en ejercicio del art. 149.1.13 CE es un juicio de inconstitucionalidad mediata, el cual antes de la STC 102/2016 se encontraba reservado al Tribunal. 
determinados apartados del art. 149.1 CE. En este supuesto, la contradicción entre las normas adoptadas por los diversos niveles no supone un juicio de inconstitucionalidad mediata o indirecta, pues las normas estatales adoptadas en ejercicio de competencias transversales estatales no se constituyen en parámetro de constitucionalidad de las normas autonómicas ${ }^{35}$.

c) Un tercer supuesto sería aquel en el que ambos niveles disponen de idéntica competencia sobre idéntico objeto. Se trataría de las denominadas competencias concurrentes que se caracterizarían por haberse atribuido la competencia sobre una misma materia y con el mismo alcance a los dos niveles territoriales $^{36}$. Las entidades territoriales podrían actuar mientras la entidad central no lo haga, pues si lo hace las normas de las entidades territoriales que se le opongan quedarán desplazadas en virtud del principio de prevalencia ${ }^{37}$.

En los tres supuestos recién examinados no nos encontramos ante supuestos de control de constitucionalidad mediata o indirecta, pues la norma estatal

35 Una norma autonómica dictada en ejercicio de una competencia material propia que contradice una normativa estatal anterior dictada en ejercicio de una competencia transversal (art. 149.1.1 CE) puede ser declarada nula por el TC cuando resuelve un recurso de inconstitucionalidad, pero no como consecuencia de vulnerar la distribución de competencias, tampoco por vulnerar el principio de prevalencia, que en realidad no es un principio que prohíba nada, sino como consecuencia de vulnerar el principio de lealtad autonómico o de cooperación leal (Quadra-Salcedo Janini, 2008: 193). Sin embargo, la norma autonómica anterior desplazada en virtud de la prevalencia del derecho estatal posterior será sin duda aplicable en el futuro si, por ejemplo, la norma estatal es derogada y no sustituida.

36 Así, recientemente la STC 177/2016, de 20 de octubre, ha recordado que desde la STC 49/1984 en materia de cultura la distribución competencial es concurrente ex art. 149.2 CE.

37 Un relevante sector doctrinal considera que este sería el único supuesto en el que cabría la aplicación del principio de prevalencia del derecho estatal sobre el derecho autonómico. E incluso van más allá, pues consideran que, dadas las características de nuestro sistema constitucional de distribución de competencias — que se funda en la idea de que cuando el bloque de la constitucionalidad atribuye una determinada competencia lo hace con carácter exclusivo, con la pretensión de que la facultad de que se trate sobre el ámbito material que sea pueda tan solo ser ejercida válidamente bien por el Estado bien por la Comunidad Autónoma, pero no por ambos simultáneamente y con la misma extensión-, la regla de prevalencia seria de dudosa utilidad en el ordenamiento espańol (De Otto, 1989: 282; Carmona Contreras, 1998:143). En esta línea, para Fernández Farreres (2005: 433) «el precepto constitucional que recoge el principio de prevalencia sería un precepto prácticamente vacío de contenido». 
prevalente no se constituye en parámetro de constitucionalidad de la norma autonómica desplazada, cosa que, por el contrario, sí ocurre en el supuesto de la existencia de una contradicción entre la ley autonómica y la normativa básica estatal. Fue precisamente esta razón - la consideración de que el juicio de compatibilidad entre ambas normas es siempre un juicio de constitucionalidad de la ley autonómica- la que llevó al Tribunal a mantener durante más de dos décadas que en el caso de que un juez apreciase la contradicción entre ambas normas debía - si consideraba que la norma básica estatal había sido adoptada en ejercicio de las legitimas competencias del Estado- plantear la cuestión de inconstitucionalidad frente a la ley autonómica sin poder considerarla desplazada en aplicación del principio de prevalencia del art. 149.3 CE

\section{EL SUPUESTO CONTROVERTIDO DE APLICACIÓN DE LA PREVALENCIA: EL ÁMBITO DE LAS COMPETENCIAS COMPARTIDAS}

De acuerdo con la doctrina del TC, la norma autonómica que contradice la ley básica —-material y formal—invade el ámbito de la competencia estatal, incurriendo por ello en un vicio de incompetencia vulnerador del orden constitucional de distribución de competencias (STC 60/1993, de 18 de febrero, FJ 1). Tal concepción tendrá como corolario hasta la STC 102/2016 que no cabe la aplicación de la prevalencia prevista en el art. 149.3 CE en el ámbito de las competencias compartidas.

\section{LA DOCTRINA CONSTITUCIONAL TRADICIONAL QUE EXCLUYE EL USO DEL PRINCIPIO DE PREVALENCIA EN LA RESOLUCIÓN DE LOS CONFLICTOS NORMATIVOS ENTRE LA LEY AUTONÓMICA Y LAS BASES ESTATALES}

El TC se planteará de forma expresa la específica cuestión de si la regla de la prevalencia es aplicable por los órganos judiciales ordinarios a los supuestos en los que la ley autonómica contradice las bases del estado en la STC 163/1995, de 8 de noviembre. En aquella ocasión el órgano proponente de la cuestión había suscitado la cuestión de su propio ámbito de jurisdicción al extraer como consecuencia de la regla de prevalencia del art. 149.3 CE un deber de «aplicación directa» de la norma básica estatal por parte de los jueces ordinarios.

El Tribunal en su respuesta se planteó "qué deba entenderse por "control de constitucionalidad", pues es éste, y no cualquier otro, el que queda reservado a este Tribunal, siendo a ese control al que queda delimitado el 
llamado "privilegio jurisdiccional" de la ley" (STC 163/1995, de 8 de noviembre, FJ 4). Para el Tribunal estamos ante un control de constitucionalidad en aquellos supuestos en los que el control se suscita, de forma única y directa, respecto de un precepto contenido en la Constitución, pero también en aquellos otros en los que, como consecuencia de la configuración constitucional de la distribución de las competencias normativas, dicho control debe tener lugar, en los términos del art. 28.1 LOTC, respecto de «Leyes que, dentro del marco constitucional, se hubieran dictado para delimitar las competencias del Estado y las diferentes Comunidades Autónomas o para regular o armonizar el ejercicio de las competencias de éstas». Para el Tribunal, en el caso de la distribución de competencias a través del criterio bases/desarrollo, el control del respeto de este criterio de distribución es, sin duda, "control de constitucionalidad» en el sentido del art. 153 a) CE, lo que permite al Tribunal controlar, ante la impugnación de una ley autonómica dictada en una materia en la que a la comunidad autónoma le corresponde el desarrollo, si el mencionado criterio de distribución ha sido respetado incorporando como canon de constitucionalidad las normas dictadas por el Estado en ejercicio de su competencia básica. En tales supuestos el control de constitucionalidad es "mediato o indirecto", pues la eventual inconstitucionalidad dimanará de la infracción por la ley autonómica de la ley dictada en ejercicio de la competencia que sobre las bases de la materia corresponde al Estado. El hecho de que el control de la adecuación de la ley autonómica a las bases estatales sea un «control de constitucionalidad» lleva al Tribunal a afirmar que en tales supuestos el control de constitucionalidad de las leyes corresponde en exclusiva al TC, pues «los Jueces y Tribunales integrantes del Poder Judicial no pueden pretender una excepción a lo previsto en los arts. 163 y 153 a) C.E. [...] como consecuencia de un determinado entendimiento de lo previsto en el art. 149.3, inciso segundo, in fine, C.E.» (STC 163/1995, de 8 de noviembre, FJ 4) ${ }^{38}$.

38 Ciertamente, sería posible realizar una construcción que pusiese en tela de juicio el alcance que el Tribunal ha dado a la «inconstitucionalidad mediata», lo que supondría negar aquella visión que considera que la ley básica estatal completa la Constitución y que, por ello, la ley autonómica que es contraria a aquella resulta inválida por inconstitucional. Así, si se restringiese la interpretación del alcance del concepto de inconstitucionalidad a la inmediata y se asumiese que en el ámbito de lo básico la Constitución deja un espacio al legislador estatal, el único juicio de inconstitucionalidad que cabría hacer es el de si el Estado ha desbordado ese espacio. Determinado ello, la contradicción entre la ley básica y la ley autonómica sería un puro juicio de compatibilidad. 
A partir de entonces, el Tribunal Constitución considerará que si los órganos judiciales inaplican una norma legal autonómica por considerarla contraria a las bases estatales, sin plantear la cuestión de inconstitucionalidad, desbordan los contornos propios de su potestad jurisdiccional (art. 117.1 $\mathrm{CE})$, y con ello vulneran los derechos fundamentales consagrados en los arts. 24.1 y 24.2 CE (por todas, la reciente STC 195/2015, de 21 de septiembre).

Así, apenas dos días antes de que el Pleno del TC revocase su doctrina previa en la STC 102/2016, de 25 de mayo, la Sala Primera del propio Tribunal en su STC 98/2016, de 23 de mayo, con un solo voto particular discrepante, todavía aplica su doctrina tradicional al otorgar el amparo solicitado por el Ayuntamiento de Toledo por la vulneración de los derechos a la tutela judicial efectiva (art. 24.1 CE) y a un proceso con todas las garantías (art. 24.2 CE), «al proceder los órganos judiciales a la inaplicación de la norma autonómica por considerarla contraria a la ley básica estatal, sin plantear la cuestión de inconstitucionalidad, conforme a lo dispuesto en el art. 163 CE y la jurisprudencia de este Tribunal» (STC 98/2016, de 23 de mayo, FJ 2).

\section{LA REVOCACIÓN DE LA DOCTRINA TRADICIONAL EN DOS PASOS: LAS SSTC 102/2016 Y 204/2016}

La revocación de su doctrina tradicional se ha realizado por el TC en dos pasos sucesivos. En el primero parece establecer una excepción a tal doctrina únicamente cuando concurran una serie de circunstancias muy concretas. Circunstancias que se producían en el asunto resuelto por la STC 102/2016, pero también en los asuntos resueltos poco después por las SSTC 116/2016, de 20 de junio, y 127/2016, de 7 de julio, y por el ATC 167/2016, de 4 de octubre.

Sin embargo, en un segundo paso, realizado en la STC 204/2016, se amplía el alcance de la revocación a través de la generalización de la prevalencia a supuestos en los que tales concretas circunstancias no se dan.

\subsection{Un primer paso: ¿̇una tímida revocación de la doctrina tradicional fundada en una suerte de doctrina de acto aclarado?}

La STC 102/2016, de 25 de mayo, resuelve mediante un fallo de inadmisión la cuestión de inconstitucionalidad que se plantea por el Tribunal 
Superior de Justicia de Galicia en relación con el art. 32.1 de la Ley 5/1997, de 22 de julio, de Administración Local de Galicia ${ }^{39}$, que exige un régimen de mayorías cualificadas para la fusión de municipios que resulta contrario al régimen de mayorías fijado en el art. 47.2 a) de la Ley 7/1985, de 2 de abril, Reguladora de las Bases de Régimen Local (LBRL) que fue modificada en este punto por la Ley 57/2003, de 16 de diciembre, de medidas para la modernización del gobierno local ${ }^{40}$.

El TC inadmite en sentencia la cuestión de inconstitucionalidad planteada al considerar que el órgano judicial le pregunta «sobre la constitucionalidad de una norma [la autonómica] que no resulta aplicable al caso [al haber quedado desplazada por la obligación judicial de aplicar el principio de prevalencia del art. 149.3 CE]», con lo que no se puede considerar cumplido el denominado juicio de aplicabilidad, que es uno de los requisitos procesales enumerados en el art. 35.2 LOTC en desarrollo de lo dispuesto en el art. 163 $\mathrm{CE}^{41}$, y cuya observancia tiende a evitar que la cuestión de inconstitucionalidad se convierta en un medio de impugnación directo y abstracto de la validez de la ley.

La incompatibilidad de la norma autonómica con la norma estatal básica determinaría la inaplicabilidad de la primera — por aplicación del principio de prevalencia del art. 149.3 CE-y por tanto determinaría la falta de una de las condiciones exigidas para la admisibilidad de la cuestión de inconstitucionalidad: que se trate de norma con rango de ley, aplicable al caso.

Ciertamente forma parte del conjunto de las facultades inherentes a la potestad de juzgar, privativa de los jueces y tribunales ordinarios por mandato de la propia Constitución (art. 117.3 CE), la de seleccionar la norma jurídica

39 De acuerdo con el cual «las alteraciones de términos municipales podrán, asimismo, ser tramitadas, con carácter voluntario, por los Ayuntamientos interesados. En tal caso, el expediente será iniciado por los acuerdos de los respectivos Ayuntamientos, adoptados con el voto favorable de las dos terceras partes del número de hecho y, en todo caso, de la mayoría absoluta del número legal de miembros de la corporación».

40 De acuerdo con el cual «se requiere el voto favorable de la mayoría absoluta del número legal de miembros de las corporaciones para la adopción de acuerdos en las siguientes materias: a) Creación y supresión de municipios y alteración de términos municipales».

41 Así, de acuerdo con el art. $163 \mathrm{CE}$ «cuando un órgano judicial considere, en algún proceso, que una norma con rango de ley, aplicable al caso, de cuya validez dependa el fallo, pueda ser contraria a la Constitución, planteará la cuestión ante el Tribunal Constitucional en los supuestos, en la forma y con los efectos que establezca la ley, que en ningún caso serán suspensivos». 
aplicable al caso concreto de entre las varias posibles, su interpretación y la subsunción en ellas de los hechos. Sin embargo, la doctrina tradicional del TC venía considerando que no era un juicio sobre la norma aplicable aquel que se produce en el ámbito de la relación norma estatal básica-norma autonómica de desarrollo, pues en tal supuesto la facultad de seleccionar la norma jurídica aplicable al caso concreto no alcanza a desplazar una ley postconstitucional (la autonómica) ante un eventual juicio de incompatibilidad mediato con la Constitución $^{42}$.

En la STC 102/2016, de 25 de mayo, el TC considera, explícitamente, que debe apartarse de la doctrina tradicional «en un caso como el que da origen a la presente cuestión de inconstitucionalidad en que la legislación autonómica no ha hecho sino reproducir la legislación básica, y ésta se modifica después en un sentido incompatible con aquella legislación autonómica».

Aparentemente la revocación de la doctrina previa solo se daría en aquellos supuestos en los que concurriesen las concretas circunstancias que se daban en el asunto resuelto por la STC 102/2016 ${ }^{43}$. Así, en efecto, el propio TC en algún auto de inadmisión posterior a esta resolución, pero anterior a la STC 204/2016, había subrayado que el apartamiento de su doctrina tradicional se producirá siempre que concurran las concretas circunstancias que están presentes en el asunto resuelto en la primera sentencia referida: esto es, que se trate de un caso de «inconstitucionalidad indirecta o mediata»; "sobrevenida» ${ }^{44}$; que «la legislación autonómica no ha[ya] hecho sino reproducir la legislación básica ${ }^{45}$, y ésta se [haya] modifica[do] después en un sentido incompatible con aquella legislación

42 Para el TC el supuesto de una norma autonómica de desarrollo contraria a la ley básica estatal es un supuesto en el que una norma con rango de ley (la autonómica), aplicable al caso, de cuya validez depende el fallo es contraria a la Constitución (art. 163 CE) o, más precisamente, al bloque de la constitucionalidad, del que forman parte las leyes básicas (art.28.1 LOTC) [STC 195/2015, de 21 de septiembre, FJ 6].

43 Críticos con la falta de claridad de la nueva doctrina se han mostrado Requejo y Ahumada en Requejo Pagés et al. (2016).

44 Tal como dispone la STC 102/2016, FJ 2.

45 En la STC 102/2016 se señala que «la Comunidad Autónoma de Galicia, al incluir en la Ley 5/1997, de 22 de julio, su artículo 32.1, no lo hizo reclamando una competencia propia, sino por puro mimetismo con la regulación contenida en la legislación básica que aquella ley pretendía desarrollar. Este es uno de los casos en los que la aplicación del principio de prevalencia del derecho estatal no determina la derogación de la norma autonómica ni ha de conducir a su nulidad por inconstitucionalidad sobrevenida, sino que puede resolverse, como ha hecho la Xunta de 
autonómica» ${ }^{46} \mathrm{y}$, además, que "el Tribunal ya se ha[ya] pronunciado en favor del carácter básico de la regulación [estatal] ${ }^{47}$ " [ATC 167/2016, de 4 de octubre $]^{48}$.

Así, precisamente tales características concurrirán en los asuntos resueltos por las posteriores SSTC 116/2016, de 20 de junio, y 127/2016, de 7 de julio, por lo que el TC inadmitirá las cuestiones en aplicación de la doctrina establecida en la STC 102/2016.

Se trataría de una excepción de la obligación de plantear cuestión de inconstitucionalidad cuando se diese una suerte de supuesto de «acto aclarado" por parte de la doctrina previa del propio TC que ya hubiese declarado el carácter básico de la norma estatal ${ }^{49}$. Los órganos judiciales tendrían la capacidad, o más bien la obligación, de inaplicar las leyes autonómicas cuando el TC hubiese proporcionado una orientación suficiente para $\mathrm{ello}^{50}$, permitiendo «una aplicación racional y sin dilaciones indebidas del sistema jurídico complejo propio del Estado de las autonomías creado por la Constitución» ${ }^{51}$ sin poner en riesgo la seguridad jurídica.

Galicia, inaplicando la ley autonómica por considerar prevalente la posterior legislación básica estatal» FJ 6.

46 Tal como dispone la STC 102/2016, FFJJ 2 y 3.

47 Tal como dispone la STC 102/2016, FJ 6.

48 Precisamente el voto particular de la magistrada Asúa en la STC 204/2016 señala "que la doctrina perfilada en la STC 102/2016 se aplicaba a un supuesto muy especial caracterizado por la concurrencia de tres circunstancias: el carácter de lex repetita de la norma autonómica, la inexistencia de competencia autonómica alguna en el momento en que se dicta la norma autonómica y el carácter básico de la norma estatal previamente declarado por este Tribunal».

49 Recordemos que de acuerdo con la doctrina del acto aclarado el juez nacional no tiene obligación de plantear la cuestión prejudicial acerca de la interpretación de una norma de derecho de la Unión ante el TJUE cuando el propio Tribunal ya haya tenido ocasión de pronunciarse al respecto (STJ de 27.3.1963, asuntos acumulados 28, 29, 30/62, asunto Da Costa). Las excepciones a la obligación de los tribunales nacionales de última instancia de plantear cuestión prejudicial ante el TJUE han sido recogidas en la STJ de 6.10.1982, 283/81, asunto CILFIT.

50 Esta interpretación iría en línea con la «propuesta descentralizadora» de control de constitucionalidad de la ley realizada en su día por Ferreres, basada en la vinculación de los jueces ordinarios a la doctrina del Tribunal y que les permitiría inaplicar una ley directamente en lugar de plantear una cuestión de inconstitucionalidad si la invalidez de aquella resultase clara por haberse pronunciado ya el TC sobre las cláusulas constitucionales relevantes. Propuesta recogida en Ferreres (2011: 179 y ss.).

51 Tal y como se afirmaba en el voto particular a la STC 1/2003, de 16 de enero. 


\subsection{Un segundo paso: la generalización de la prevalencia en los supuestos de inconstitucionalidad mediata sobrevenida}

Sin embargo, el apartamiento por parte del TC de su doctrina tradicional no solo se producirá cuando concurran las referidas circunstancias ${ }^{52}$. En efecto, en el asunto resuelto por la reciente STC 204/2016, de 1 de diciembre, no concurrían tales circunstancias y el Tribunal, no obstante, afirmará que «la razón de decidir de aquella Sentencia [la STC 102/2016] sirve para resolver también el presente proceso constitucional».

Así, en la STC 204/2016 el Tribunal reconoce que «a diferencia del supuesto resuelto por la STC 102/2016, en el presente caso la norma de cuya constitucionalidad duda el Juzgado de lo Contencioso-administrativo n. ${ }^{\circ} 4 \mathrm{de}$ Bilbao $^{53}$ no reproduce precepto alguno estatal de carácter básico, sino que se trata de un precepto dictado en ausencia de legislación básica estatal $\aleph^{54}$. En efecto, el precepto autonómico cuando se dictó (1989) no podía reproducir base alguna, pues esta no existía y solo sobrevenidamente, en 2007, se habría establecido un precepto básico en la materia, cuando el Estado adoptó el art. 97 de la Ley 7/2007, de 12 de abril, del Estatuto Básico del Empleado Público ${ }^{55}$. Al contrario que en el asunto resuelto por la STC 102/2016, en el

52 Como había vaticinado el voto particular de la magistrada Asúa a la STC 102/2016, «se deja abierta la puerta a la aplicación de este "cambio doctrinal” a otros supuestos» pues "puede aventurarse [...] que este cambio de criterio tendrá lugar no solo en asuntos idénticos al presente, pues, como se señala en el fundamento jurídico 6 , este es uno de los casos en los que la aplicación del principio de prevalencia del "derecho estatal no determina la derogación de la norma autonómica”».

53 El Juzgado de lo Contencioso-administrativo núm. 4 de Bilbao plantea cuestión de inconstitucionalidad del art. 89.2 de la Ley 6/1989, de 6 de julio, de la Función Pública Vasca, por contravenir el art. 97 de la Ley 7/2007, de 12 de abril, del Estatuto Básico del Empleado Público, dictado por el Estado al amparo del art. 149.1.18 CE, en el que se establece un plazo de prescripción para faltas leves — seis meses-, distinto e incompatible con el establecido en la norma autonómica —un mes-.

54 Pues, en efecto, en la STC 37/2002 el Tribunal había negado la existencia de bases en materia de sanciones disciplinarias, «las cuales, en consecuencia, pueden ser libremente reguladas por las respectivas normas autonómicas al determinar el régimen estatutario de sus propios funcionarios públicos», cosa que habría hecho en su momento, y en ausencia por tanto de normativa básica en la materia, el art. $89.2 \mathrm{de}$ la Ley 6/1989, de 6 de julio, de la Función Pública Vasca.

55 Dicho precepto ha sido posteriormente derogado e incorporado, con el mismo contenido, al art. 97 del Real Decreto Legislativo 5/2015, de 30 de octubre, por el que se aprueba el texto refundido de la Ley del Estatuto Básico del Empleado Público. 
asunto resuelto por la STC 204/2016 la comunidad autónoma no reprodujo en su momento la legislación básica, pues tal legislación no existía.

Pero, asimismo, y a pesar de que no se afirme explícitamente en la STC 204/2016, en el asunto que la misma resuelve tampoco concurriría una segunda circunstancia presente en la STC $102 / 2016^{56}$, y es la circunstancia de que el Tribunal ya se hubiese pronunciado en favor del carácter básico de la regulación estatal, pues antes de la STC 204/2016 el TC no se habría pronunciado sobre el carácter básico del art. 97 del $\mathrm{EBEP}^{57}$, que sería la norma que se ve contradicha por el art. 89.2 de la Ley 6/1989, de 6 de julio, de la Función Pública Vasca.

No obstante no concurrir las características presentes en los asuntos previamente resueltos, el TC afirmará sin mayor explicación que «la razón de decidir de aquella Sentencia [la 102/2016] sirve para resolver también el presente proceso constitucional», pues de acuerdo con la STC 204/2016 «en ambos casos se trata de una ley autonómica a la que, en el momento en que se dictó, no podía imputarse vicio alguno de inconstitucionalidad, y que, sin embargo, deviene incompatible con una ley básica del Estado aprobada con posterioridad ${ }^{58}$.

Basta por tanto que se trate de un caso de «inconstitucionalidad mediata sobrevenida" para que el órgano judicial deba, salvo que tenga dudas en relación con la constitucionalidad de la norma estatal básica, dar preferencia, en aplicación de la regla de prevalencia del art. 149.3 CE, a la norma estatal y desplace la norma autonómica que la contradiga. Se produce, como ha señalado la magistrada Asúa, «la generalización incondicionada de la doctrina de

56 El voto particular de la magistrada Asúa señala que la STC 204/2016 se conforma con constatar la falta de identidad de una de las circunstancias que concurrían en el asunto resuelto por la STC 102/2016 y no se pronuncia con respecto a las demás.

57 Aunque el TC no se haya pronunciado, ciertamente cabría sostener el carácter básico del precepto estatal, pues el art. 97 EBEP, ubicado en el título VII que se intitula "Régimen disciplinario», en tanto norma que determina el plazo de prescripción de las faltas leves, se integra en el régimen disciplinario de los funcionarios públicos que de acuerdo con la doctrina del Tribunal es uno de los aspectos esenciales de la regulación de su régimen estatutario [SSTC 37/2002, de 14 de febrero, FJ 8 y 176/2015, de 22 de julio, FJ 4 a)].

58 El Tribunal ha hecho suya la posición, en su día minoritaria, contenida en el voto particular a la STC $1 / 2003$, de 16 de enero, en virtud de la cual «si el Juez estima que la ley estatal es básica, tanto material como formalmente deberá fallar de conformidad con la ley estatal, en su caso inaplicando la ley autonómica que resulta incompatible con ella, exactamente igual que si la ley de la Comunidad Autónoma contradijera disposiciones del Derecho comunitario». 
la prevalencia», pues «la doctrina especial de la prevalencia [...] como excepción a la doctrina general de la obligación judicial de plantear cuestión de inconstitucionalidad, y que fue circunscrita a la concurrencia de tres requisitos, aparece ya liberada de la rémora de esos tres requisitos y se convierte en una doctrina con vocación de generalidad. Solo se mantiene la necesidad de plantear la cuestión de inconstitucionalidad cuando el órgano judicial dude expresamente del carácter básico de la norma estatal ${ }^{59}$.

No obstante lo anterior, el Tribunal Constitucional ha circunscrito la capacidad de los órganos judiciales de aplicar la prevalencia a los supuestos de inconstitucionalidad mediata sobrevenida, esto es, cuando la contradicción se produce como consecuencia de la modificación de las bases del Estado con posterioridad a la adopción de la ley autonómica ${ }^{60}$. Así, en efecto, la Sala Segunda en su STC 1/2017, de 17 de enero, ha estimado el recurso de amparo suscitado por la Generalitat Valenciana frente a una resolución judicial que inaplica una ley autonómica y aplica la norma básica estatal por considerar que aquella inaplicación, sin plantear cuestión de inconstitucionalidad, ha vulnerado el derecho fundamental a un proceso con todas las garantías (art. 24.2 CE). El Tribunal considera que en el caso resuelto en la STC 1/2017 no cabe que el órgano judicial aplique la nueva doctrina de la prevalencia porque no se trata de un supuesto de inconstitucionalidad sobrevenida de la norma autonómica ${ }^{61}$. Sin embargo, el hecho de que la norma estatal sea posterior o anterior a la norma regional debería ser del todo irrelevante a la hora de justificar la aplicación por un órgano judicial del principio de prevalencia, pues como regla de resolución de conflictos normativos que es, debería el órgano judicial, una vez ha considerado que la norma estatal es válida, poder aplicarla de forma prevalente ${ }^{62}$.

59 Señala Aragón (2008: XVI y ss.) que ello modifica una de las características básicas de nuestro Estado autonómico: la igual posición en nuestro sistema de fuentes de la ley estatal y la ley autonómica, haciendo de peor condición a estas segundas.

60 En la línea recogida en su día por Lasagabaster Herrarte (1991: 145 y ss.).

61 Señala el Tribunal que no se dan los presupuestos que justificaron la STC 102/2016 y posteriores, a saber, la repetición por una ley autonómica de una norma básica del Estado y la posterior modificación de esa normativa básica en un sentido incompatible con aquella legislación autonómica. Y tampoco se trata de un supuesto de ausencia de norma básica y posterior dictado de esta en un sentido igualmente incompatible con la primera (STC 204/2016). Para el Tribunal, en el caso la ley autonómica (Ley 14/2005 de la Comunidad Valenciana) ya se oponía a la ley de contratos del Estado vigente en el momento de dictarse aquella (Real Decreto Legislativo 2/2000, de 16 de junio).

62 Así lo afirma refiriéndose al sistema alemán Tejedor Bielsa (2000: 51) y más recientemente Fernández Farreres (2017) y Alonso Mas (2017: 261) en relación con nuestro 


\section{LAS CONSECUENCIAS DE LA NUEVA DOCTRINA SOBRE EL MODELO DE JUSTICIA CONSTITUCIONAL}

Los magistrados discrepantes con la nueva doctrina consideran que el principio de prevalencia, aplicado en aquellas concretas controversias que se refieren a leyes autonómicas que contradicen la normativa básica del Estado, acercaría el modelo de justicia constitucional español al modelo descentralizado americano, pues el órgano judicial se encontraría autorizado por el art. 149.3 CE para hacer por sí mismo el juicio de compatibilidad de la ley autonómica con la norma estatal considerada básica ${ }^{63}$. Tal juicio de compatibilidad es el mismo juicio que tendrá que realizar el TC cuando al resolver un recurso de inconstitucionalidad frente a la ley autonómica tenga que determinar, en aplicación del principio de competencia, la inconstitucionalidad mediata o indirecta de aquella. La diferencia se encuentra en la consecuencia que se desprendería según quién sea el que haga el juicio. La incompatibilidad de la norma autonómica con la norma estatal básica determinaría, cuando tal juicio lo hace el órgano judicial, la inaplicabilidad de la primera en el caso concreto, pero, cuando lo hace el TC, la invalidez de la primera con efectos erga omnes. A pesar de que la consecuencia pueda ser distinta, lo cierto es que el motivo por el que el juez ordinario inaplica o el juez constitucional invalida una ley es el mismo: la incompatibilidad entre la ley autonómica y las bases estatales.

El modelo centralizado de justicia constitucional supone otorgar un privilegio jurisdiccional al legislador en virtud del cual las leyes solo pueden ser anuladas por el TC (Zagrebelsky, 1995: 58-65). Así, siguiendo a Ferreres Comella, las características de un modelo centralizado de justicia constitucional serían dos: a) su centralización, solo el TC puede controlar definitivamente la validez constitucional de la ley y en consecuencia los órganos judiciales no pueden por su propia autoridad inaplicar una ley por estimar que viola la Constitución ${ }^{64} ; \mathrm{y}$ b) el carácter abstracto del control, la finalidad del proceso que se abre (por iniciativa de los legitimados para interponer el recurso de inconstitucionalidad o por iniciativa de los órganos judiciales vía cuestión de inconstitucionalidad a los

sistema.

63 Para Rubio Llorente (1989: 33), cuando el juez ordinario inaplica la ley autonómica «no está, en rigor, juzgando sobre la validez constitucional de la Ley autonómica, sino resolviendo un conflicto de normas cuyo supuesto implícito es el de la constitucionalidad de la Ley estatal, que él, por el contrario, no podría por sí mismo negar».

64 El constituyente habría querido sustraer al juez ordinario la posibilidad de inaplicar una ley posconstitucional ante un eventual juicio de incompatibilidad con la Constitución (STC 17/1981, de 1 de junio, FJ 1). 
efectos de resolver un caso concreto que tienen planteado) es determinar si una ley es o no inconstitucional (Ferreres Comella, 2003).

El principio de prevalencia tal y como ha sido interpretado en la reciente doctrina del TC supone efectivamente una excepción a un modelo centralizado puro de justicia constitucional si se considera que abre la posibilidad de que los órganos judiciales efectúen una inaplicación de una ley autonómica por contravenir mediatamente la Constitución, pues lo que caracteriza el modelo de control centralizado no es solo el monopolio del TC para declarar con efectos erga omnes la nulidad de las normas con rango de ley, sino también la imposibilidad para los jueces ordinarios de inaplicar aquellas por contravenir la Constitución.

El hecho de que tal excepción al modelo centralizado de justicia constitucional pudiese estar justificada en la previsión en la propia norma fundamental del principio de prevalencia (art. 149.3 CE) no supone que las consecuencias que se ha señalado que tiene la adopción de tal excepción no sean dignas de tenerse en cuenta.

Así, en efecto, la magistrada Asúa destaca en su voto particular a la STC 102/2016 que la aplicación de la prevalencia «conlleva un riesgo cierto de inseguridad jurídica y de pérdida de uniformidad en la interpretación y aplicación de las normas del bloque de la constitucionalidad», hurtando al Tribunal su conocimiento por la vía del art. 163 CE.

Para el voto particular del magistrado Martínez Vares a la STC 204/2016, la nueva doctrina supone una grieta abierta en nuestro modelo concentrado de justicia constitucional, «al abrir una vía de entrada al modelo de control difuso de constitucionalidad de las leyes sin los reajustes necesarios para evitar la inseguridad jurídica y preservar la posición de los Parlamentos autonómicos».

Dos serían, por tanto, las consecuencias de reconocer una excepción en el modelo centralizado de justicia constitucional —independientemente de que la misma se pueda justificar en el texto constitucional o sea una construcción jurisprudencial—: una mayor inseguridad jurídica (Aragón Reyes, 2008: XVII) y una falta de preservación de la posición de los Parlamentos autonómicos. Precisamente estas dos consecuencias afectan a dos de las razones que doctrinalmente han justificado la adopción de un modelo centralizado de justicia constitucional frente a un modelo descentralizado, la seguridad jurídica y el carácter democrático de la obra del Parlamento.

a) En lo que se refiere a la inseguridad jurídica ${ }^{65}$, la misma provendría fundamentalmente del riesgo de contradicciones entre los diversos órganos

65 Señala Ferreres Comella (2003: passim) cómo en un modelo descentralizado se podría generar inseguridad jurídica como consecuencia de tres factores: la existencia 
judiciales a la hora de determinar la compatibilidad de las leyes autonómicas con la normativa básica estatal ${ }^{66}$.

La determinación de cuando una norma autonómica es compatible con las bases no es siempre sencilla de realizar.

Así, a titulo de ejemplo, cabe recordar que el TC en la STC 26/2016, de 18 de febrero, interpretó que cuando la base estatal establece que la sustitución transitoria de profesores en el ámbito educativo se producirá únicamente cuando hayan transcurrido diez días lectivos desde la situación que da origen a dicho nombramiento, se debía entender que aunque se establezca un plazo cerrado y concreto, se trataba de un plazo mínimo, que si bien no podía ser reducido por las Administraciones educativas autonómicas, sí podía ser ampliado. En un caso como el descrito, con la nueva doctrina constitucional, la interpretación de la compatibilidad entre las bases y la ley autonómica podría corresponder a los órganos judiciales y podría darse una falta de uniformidad en aquella si algunos inaplican los eventuales plazos recogidos en la normativa autonómica, ampliando o reduciendo los establecidos en las bases, mientras que otros aplican los plazos autonómicos por considerar que las bases recogen un plazo mínimo.

Igualmente problemático podrán ser aquellos supuestos en los que el legislador no haya identificado dentro de una norma aquellos preceptos que son básicos — como consecuencia de que la norma contenga una regulación completa de una materia con vocación de aplicarse en su integridad, por ejemplo, a la Administración del Estado (pues se trata de una regulación sobre funcionarios) o a las obras de interés general (al establecer una regulación de

de una división del poder judicial en varias jurisdicciones (civil, penal, contencioso-administrativa), presididas cada una de ellas por un tribunal superior específico, el hecho de que estos tribunales tienen una composición muy numerosa, y el hecho de que en la tradición del civil law no opere la doctrina del precedente.

66 En mi opinión, yerra en alguna medida el voto particular a la STC 102/2016 al señalar que la inseguridad jurídica y la pérdida de uniformidad en la interpretación y aplicación de las normas proviene de la posibilidad de que sean los órganos judiciales los que realicen el juicio acerca del carácter formal y materialmente básico de la norma estatal, pues el juicio positivo de constitucionalidad de una norma es algo consustancial a la labor judicial. En caso de que un juez considerase que la norma estatal no cumple las exigencias de lo básico, la doctrina, previa y presente, del Tribunal exige en todo caso el planteamiento de la cuestión de inconstitucionalidad, y el hecho de que otros jueces con anterioridad hayan podido realizar un juicio positivo de la norma estatal no afecta a la seguridad jurídica más allá de lo que le afecta el hecho de que una norma ha podido estar siendo aplicada durante años hasta que un juez la cuestiona ante el TC y este la anula. 
medio ambiente), pero con vocación de aplicarse a las comunidades autónomas solo en los aspectos que se consideren básicos-. En estos casos la falta de identificación de los preceptos básicos genera un alto riesgo de falta de uniformidad interpretativa ${ }^{67}$.

Con la nueva doctrina se deja la interpretación y aplicación de la distribución de competencias mediante la técnica bases-desarrollo en manos de los órganos judiciales ordinarios, los cuales, una vez han constatado el carácter básico de la norma estatal, deben realizar el juicio de compatibilidad de la ley autonómica con las bases estatales sin poder contar para realizar estos juicios con las orientaciones de un tribunal centralizado. En efecto, bajo la nueva doctrina no parece que el órgano judicial pueda plantear la cuestión de inconstitucionalidad como alternativa a su capacidad de inaplicar la ley autonómica, pues precisamente las recientes sentencias comentadas finalizan con un fallo de inadmisión de las cuestiones planteadas ${ }^{68}$. Fallo de inadmisión que se basa en que, precisamente, la aplicación por el juez ordinario de la regla de la prevalencia, al ser una regla sobre la determinación de la norma aplicable, antecede al planteamiento de la cuestión y excluye, en caso de un juicio negativo acerca de la compatibilidad de la ley autonómica y la base estatal, la posibilidad de plantear aquella en virtud del art. $163 \mathrm{CE}$, que establece como exigencia que se trate de una norma aplicable al caso de cuya validez depende el fallo.

b) En lo que se refiere a la necesidad de preservar la posición de los Parlamentos autonómicos, es indudable que en un modelo de control difuso como el que se deriva de la prevalencia de las bases estatales sobre las leyes autonómicas se priva a los representantes de los ciudadanos que elaboraron la norma de la posibilidad de alegar en defensa de la ley autonómica (Lasagabaster Herrarte, 1991: 124). Así, en el modelo centralizado de justicia constitucional la

67 Señala Lasagabaster Herrarte (1991: 150) que la aplicación del principio de prevalencia exige que el Estado señale expresamente las normas que son básicas, pues en caso contrario se dejaría en manos del juez ordinario la interpretación del alcance de lo básico.

68 La posibilidad de que los órganos judiciales puedan alternativamente inaplicar la ley autonómica o plantear cuestión ha sido defendida doctrinalmente, por ejemplo, por García Torres (2015). Esta concurrencia de la jurisdicción constitucional con la jurisdicción propia de los órganos del poder judicial ha sido sostenida igualmente en el voto particular a la STC 1/2003 que considera que tal tipo de concurrencia se ha reconocido con naturalidad por la doctrina del Tribunal en el caso de la leyes anteriores a la Constitución desde la STC 4/1981, de 2 de febrero (FJ 1), "precisamente porque, como en el caso actual, la Constitución fue aprobada cuando ya se encontraban en vigor unas leyes que, en el momento en que habían sido promulgadas, eran plenamente válidas y no contradecían preceptos entonces inexistentes». 
representación de la comunidad autónoma, tanto el Gobierno como el Parlamento, tiene la capacidad de intervenir en el proceso por el que se resuelve la cuestión de inconstitucionalidad reconociéndosele, así, al órgano que elaboró la norma la capacidad de presentar sus argumentos y defender la legitimidad constitucional de la misma ${ }^{69}$.

Sin embargo, tal posibilidad de alegar en defensa de su norma no se daría en el modelo descentralizado, pues en los pleitos de los que conocen los jueces, el Parlamento autonómico, o incluso su Gobierno, no son parte en el litigio. En estos supuestos, para que el Parlamento o el Gobierno autonómico pudieran comparecer para ser oídos, los jueces tendrían que darles traslado del asunto cada vez que una ley autonómica fuese cuestionada en un caso concreto por vulneración de las bases. De lo contrario se impediría la "prerrogativa» de los parlamentos de que sus leyes sean examinadas ante el TC, órgano integrado de manera distinta que la jurisdicción ordinaria y que está más estrechamente conectada a las instituciones democráticas (Ferreres Comella, 2011: 175).

Sea como fuere, para hacer frente a los dos riesgos señalados, el riesgo de contradicciones interpretativas entre los diversos tribunales que pongan en cuestión la seguridad jurídica en la interpretación de la distribución competencial y el riesgo de no permitir la participación de los Parlamentos autonómicos en aquellos procesos en los que se esté determinando el alcance de las competencias autonómicas, quizás sería conveniente introducir una técnica centralizadora como la existente en el sistema de la Unión Europea: una suerte de cuestión prejudicial de interpretación de las leyes autonómicas ante el TC.

En efecto, recordemos que en el ámbito del derecho de la Unión existe un mecanismo que contribuye a garantizar un importante grado de uniformidad en la interpretación de las normas europeas, y por ende a promover la seguridad jurídica frente al riesgo de contradicciones entre los diversos tribunales nacionales: la cuestión prejudicial de interpretación. Mecanismo que sirve indirectamente para realizar un juicio de compatibilidad de las normas nacionales con el derecho europeo, pues si bien, en principio, el TJUE debe pronunciarse en relación a la interpretación del derecho europeo y no sobre la concreta ley nacional, en la práctica en muchas ocasiones responde de manera más o menos indirecta a la cuestión relativa a la compatibilidad entre ambos.

69 De acuerdo con el art. 37.3 de la LOTC, «el Tribunal Constitucional dará traslado de la cuestión [...] en caso de afectar a una Ley o a otra disposición normativa con fuerza de Ley dictadas por una Comunidad Autónoma, a los órganos legislativo y ejecutivo de la misma, todos los cuales podrán personarse y formular alegaciones sobre la cuestión planteada en el plazo común improrrogable de quince días». 
En el supuesto de prever la posibilidad de una cuestión interpretativa ante el TC, este tendría la facultad de resolver con efectos erga omnes acerca de la compatibilidad entre las disposiciones autonómicas y las disposiciones básicas estatales. Este nuevo proceso permitiría paliar las consecuencias señaladas y garantizar la aplicación uniforme de la distribución de competencias en aquellos supuestos en los que el órgano judicial tuviese dudas en relación con el juicio de compatibilidad ente la ley autonómica y la norma básica estatal. Ello, ciertamente, requeriría la modificación de la LOTC para introducir este nuevo proceso ante el Tribunal que permitiera a los jueces ordinarios plantear cuestiones aunque se tratase de normas que ellos mismos pudiesen inaplicar en virtud de la nueva interpretación del principio de prevalencia. Modificación de la LOTC cuya constitucionalidad cabe fundar en la reciente doctrina del TC que ha reconocido un amplio margen de configuración al legislador democrático orgánico a la hora acomodar el modelo de jurisdicción constitucional a las necesidades y circunstancias de cada momento ${ }^{70}$.

\section{Bibliografía}

Alonso Mas, M. J. (2017). De nuevo sobre la prevalencia del derecho estatal y la inaplicación judicial del derecho autonómico. Revista de Administración Pública, 203, 235-265.

Aragón Reyes, M. (2008). Prólogo. En T. de la Quadra-Salcedo Janini. Mercado nacional único y Constitución. Madrid: CEPC.

Arroyo Gil, A. (2009). Una concepción de los principios de competencia y prevalencia en el Estado Autonómico español. Revista jurídica Universidad Autónoma de Madrid, 20, 195-217.

Balaguer Callejón, F. (1986). La Cláusula de Prevalencia del art. 149.3 y los Estatutos de Autonomía. Revista Valenciana d'estudis Autonomics, 4, 117-137.

Borrajo Iniesta, I. (2009). Artículo 149.3 CE. El orden constitucional de competencias y ordenamientos. En M. E. Casas Baamonde y M. Rodríguez-Pińeiro y Bravo-Ferrer (dirs.). Comentarios a la Constitución española. Madrid: Wolters Kluwer.

70 Así se desprende de las SSTCC 118/2016, de 23 de junio, y 185/2016, de 3 de noviembre, donde el Tribunal rechazó que nuestro ordenamiento consagrase una petrificación o congelación del modelo de jurisdicción constitucional pues ello no se compadece ni con el margen de configuración del legislador democrático ni con el carácter dinámico del ordenamiento jurídico. «Es, pues, al legislador orgánico, ex arts. $161.1 \mathrm{~d}$ ), 162.2 y 165 (en conexión con el art. 81.1) CE, a quien corresponde determinar, en cada momento, a partir de las previsiones del texto constitucional, el alcance de las competencias y el contenido de los procedimientos que corresponden a este Tribunal Constitucional» (FJ 3). 
Carmona Contreras, A. M. (1998). El ámbito de aplicación de la cláusula de prevalencia en el derecho español. En E. Hinojosa Martínez. Jurisdicción Ordinaria y Distribución competencial entre el Estado y las Comunidades Autónoma. Granada: Comares.

De Otto, I. (1981). La prevalencia del derecho estatal sobre el derecho regional. Revista Española de Derecho Constitucional, 2, 57-92. (1987). Derecho Constitucional. Sistema de Fuentes. Barcelona: Ariel.

Díez Picazo, L. M. (1989). Ley autonómica y Ley estatal. (Sobre el significado del principio de competencia en el Estado autonómico). Revista Española de Derecho Constitucional, 25, 63-86.

Fernández Farreres, G. (1991). Colisiones normativas y primacía del derecho estatal. En VV. AA. Estudios sobre la Constitución Española. Homenaje al Profesor Eduardo García de Enterría. Madrid: Civitas.

- (2005). La contribución del Tribunal Constitucionalal Estado Autonómico. Madrid: Iustel.

- (2017). ¿Puede el juez inaplicar la ley autonómica por razón de la prevalencia del derecho estatal? Revista Española de Derecho Administrativo, 186, 47-82.

Fernández Rodríguez, T. R. (1979). Autonomía y sistema de fuentes en la Constitución española y las Fuentes del Derecho. Madrid: IEF.

Ferreres Comella, V. (2003). Integración europea y crisis del modelo centralizado de justicia constitucional. Revista Vasca de Administración Pública, 65, 73-121.

- (2011). Una defensa del modelo europeo de control de constitucionalidad. Madrid: Marcial Pons.

García de Enterría, E. (1985). Estudios sobre autonomías territoriales. Madrid: Civitas.

- y Fernández Rodríguez, T. R. (1999). Curso de Derecho Administrativo. Madrid: Civitas.

García Morales, V. Y. (2015). Prevalencia en la planificación territorial [tesis doctoral]. Universidad Autónoma de Madrid. Disponible en: https://repositorio.uam.es/bitstream/ handle/10486/671680/garcia_morales_veronica_yazmin.pdf?sequence $=1$.

García Torres, J. (1988). El sistema europeo de control de constitucionalidad: La historia manifiesta la esencia, de Pedro Cruz Villalón. Revista Española de Derecho Constitucional, 24, 275-282.

(2015). Ceci a tué cela: la doctrina de la inconstitucionalidad mediata y la prevalencia de las normas estatales. En VV. AA. El juez del derecho administrativo. Libro homenaje a Javier Delgado Barrio. Madrid: Marcial Pons.

- (2016). ¿'Timidez o desmesura? Reflexiones sobre las SSTC 102/2016, 116/2016 y 127/2016 y su voto particular. Ponencia presentada en la Universidad Autónoma de Madrid el 4 de noviembre de 2016.

Hernández Corchete, J. A. (2017). La prevalencia del Derecho estatal en materia urbanística en Cuestiones actuales de Derecho Urbanístico. En Actas de las II Jornadas de la Agencia Gallega de la Legalidad Urbanistica. Thomson Reuters (en prensa).

Jiménez Campo, J. (1989). ¿Qué es “lo básico”?: legislación compartida en el Estado autonómico. Revista Española de Derecho Constitucional, 27, 39-92.

Lasagabaster Herrarte, I. (1991). Los principios de supletoriedad y prevalencia del derecho estatal respecto al derecho autonómico. Madrid: Civitas. 
Muñoz Machado, S. (1982). Derecho Público de las Comunidades Autónomas. Madrid: Civitas.

- (2006). Tratado de Derecho Administrativo y Derecho Público General, II, El Ordenamiento Jurídico. Madrid: Iustel.

Padrós Reig, C. y González Barral, J. C. (2017). El reciente resurgir de la cláusula de prevalencia del Derecho estatal. Revista General de Derecho Constitucional, 25.

Quadra-Salcedo Janini, T. (2008). Mercado Nacional Único y Constitución. Madrid: CEPC.

- (2013). Algunas novedades doctrinales en materia competencial. En Crisis y Constitución. XIXJornadas de la Asociación de Letrados del Tribunal Constitucional. Madrid: CEPC.

Requejo Pagés, J. L. (2016). El sueño constitucional. Oviedo: KRK ediciones.

- Duque Villanueva, J. C., Ortega Carballo, C. y Ahumada Ruiz, M. (2016). Doctrina del Tribunal Constitucional durante el segundo cuatrimestre de 2016. Revista Española de Derecho Constitucional, 108, 229-271. Disponible en: https://doi.org/10.18042/ cepc/redc.108.08.

Rubio Llorente, F. (1989). El bloque de constitucionalidad. Revista Española de Derecho Constitucional, 27, 9-37.

Tejedor Bielsa, J. C. (2000). La garantía constitucional de la unidad del ordenamiento en el Estado Autonómico. Competencia, prevalencia y supletoriedad. Madrid: Civitas.

Tornos Mas, J. (1984). La cláusula de prevalencia y el art. 4 de la LOAPA. En Los proceso de formación de las CCAA. Aspectos jurídicos y perspectivas politicas. Vitoria: Parlamento Vasco.

— (1991). Ley de bases y legislación de desarrollo. El problema de su articulación por modificación de la Ley de bases. La cláusula de prevalencia. Revista Española de Derecho Constitucional, 33, 29-45.

Viver I Pi-Sunyer, C. (1989). Materias competenciales y tribunal constitucional. Barcelona: Ariel.

Zagrebelsky, G. (1995). El derecho dúctil. Ley, derechos, justicia. Madrid: Trotta. 